\title{
Firm Value and the Impact of Operational Management
}

\author{
Sovan Mitra ${ }^{1}(1) \cdot$ Andreas Karathanasopoulos $^{2}$
}

Published online: 10 November 2018

(c) The Author(s) 2018

\begin{abstract}
Operational management has been gaining increasing importance in the financial industry and firms make substantial investments in operations management systems to reduce operational risk. Using a standard model of operational risk, it can be shown that pair trade profits reveal differences in relative operational performance between firms. Consequently, pair trade profits have implications for understanding operational performance. Moreover, although operations management systems are well established sources of firm value creation, their relation to pair trade profits are not well understood. In this paper we investigate the impact of operations management systems upon firm value in the financial sector. Firstly, we show that relative operational performance between firms can be evaluated from pair trade returns, providing a new method of measuring operational performance, and demonstrate this using 11,648 pair trades data, weekly stock price data and operational event data from 2000 to 2007 . Secondly, we find that pair trade returns and operational risks vary significantly by business line and event type, implying that operational systems can improve firm performance by strategically reallocating them. Thirdly, we show that investor risk aversion varies significantly with different operational risks, implying firms should manage operational systems more strategically to reduce firm value losses. Finally, this paper offers an alternative explanation to pair trade returns compared to current research.
\end{abstract}

Keywords Operational management systems · Operational risk · Operational risk management $\cdot$ Risk management $\cdot$ Risk analysis $\cdot$ Pairs trading

\section{Introduction}

Operational management and operational risk (Papazafeiropoulou and Spanaki 2015) have been gaining increasing importance in industry (Scott and Perry 2009;

\footnotetext{
Sovan Mitra

sovan.mitra@liverpool.ac.uk

1 University of Liverpool, Brownlow Hill, Liverpool L69 3BX, UK

2 University of Dubai, Academic City, Emirates Road, P.O. Box 14143, Dubai, UAE
} 
Mukhopadhyay et al. 2017; Silvestro and Lustrato 2014; Reim et al. 2016; Hora and Klassen 2013; Tazelaar and Snijders 2013) and firms make substantial investments in operations management systems (from hereon OMS) to mitigate operational risk (from hereon OR), see for instance Wang et al. (2010) and Dey (2004). The standard model of OR for firms in the financial sector (Loader 2002) implies that pair trade profits (where pair trading is defined as buying one stock and short selling another similar stock) arise due to differences in OR between the 2 firms (see Sect. 2 for a detailed explanation). Therefore pair trade (from hereon PT) profits have direct implications for understanding OMS performance between firms and relative firm value growth between them.

The recognition of the relevance of OMS to firm value is becoming increasingly important as firms now regard OMS as a strategic resource for competitive advantage; see for instance Wu et al. (2012), Ülengin et al. (2014), Moormann and LochteHoltgreven (1993) and Zack (2007), moreover (Martinsons et al. 1999) claim that IT investment is important to achieving business goals. Despite this, there is a lack of literature on OMS, firm value (or equivalently share price) and PT. This is even more surprising given that OMS are an accepted source of firm value creation; see for instance Jiang et al. (2006), Sillince and Sykes (1993), Chircu and Mahajan (2006), Im et al. (2001) and Dos Santo et al. (1993) to name a few articles.

The lack of literature on OMS and stock prices (and more specifically PT) means there has been little analysis on the relation of PT profits to OMS, and so it is not well understood. For instance, do PT profits imply OR and OMS are significant factors in firm performance differences and to what extent? Do OMS in particular operational areas impact PT returns and firm value growth more (or less) than in other areas? Is the degree of risk associated with OR in PT returns too high or low? The fact that firms do not understand the relation of PT profits to OMS is surprising given that firms are constantly seeking opportunities for relative firm value growth, and PT returns signal differences in relative firm value growth (since PT returns arise from difference in firm value growth or stock prices).

The fact that OMS are sources of firm value growth and yet there are few studies relating OMS to PT suggest that firms do not fully comprehend the impact of OMS. This can be attributed to a number of reasons. Firstly, most research relating to OMS and firm value has focussed on singular aspects of OMS (see for instance Gillet et al. 2010; Kallenberg 2007). Hence the understanding of various aspects of OMS upon firm value has not been analysed, for instance the various aspects of OMS that lead to competitive advantages.

Secondly, most OMS literature investigates the firm's absolute or individual growth independent of other firms (see for instance Meng and Lee 2007), yet PT profits relate to relative firm value growths rather than absolute growth. The current literature does not distinguish between firm growth that is an improvement in comparison to its peers, or growth that is in line with firms in the same sector. Consequently, the relation between OMS and its contribution to PT profits are not well understood; this has been further exacerbated by the view that OMS were not previously viewed as strategic resources for competitive advantage.

Thirdly, the literature on PT tends to focus on trading strategies (e.g. Huck 2010; Elliott et al. 2005); these strategies employ quantitative methods to identify and trade 
pairs of stocks based on their historic price patterns. Consequently, the relationship between PT profits and OMS are not analysed. Hence the impact of OMS upon relative firm value growth (or PT profits) is not examined.

In the past decade the literature and interest in OMS and OR management (from hereon ORM) has increased. For instance, models now exist to quantify OR relating to OMS (Chorafas 2004; Loader 2002) and it is now possible to obtain data on OMS that catalogue their (operational) losses. We can therefore now quantitatively and more accurately assess the impact of OMS upon a firm. In particular, we able to investigate OMS and OR issues with respect to particular operational events and different business lines.

In this paper we investigate OMS and their relation to PT returns, or equivalently relative firm value growth. We use data from 11,648 pairs trades, weekly stock price data and operational event data from 2000 to 2007. We analyse PT returns and OR during operational events, as well as analyse other statistical properties of interests such as skewness. We investigate the PT returns and the OMS's relation with respect to OR, operational event types and business lines.

This paper makes a number of contributions. Firstly, we show that relative operational performance between firms can be evaluated from pair trade returns, providing a new method of measuring operational performance. This is substantiated by empirical results that show that significant PT returns occur during operational events, implying that OMS are a significant factor in relative firm value growth or performance. Secondly, we find that there is significant variation in PT returns and OR by business line and event type, implying that OMS contribution to relative firm value can be improved by strategically focussing on particular areas. Thirdly, we show that investor risk aversion varies significantly with different operational event types and business lines, hence firms should risk manage more strategically to minimise losses in firm value. Finally, our paper provides a more consistent explanation of PT returns compared to current financial explanations, by attributing them to OR factors.

The rest of the paper is organised as follows: in the next section we introduce PT, OR and the motivation of our study, providing a literature review of current research. We then introduce our methodology, data, discuss our results and analyse them. We then finally end with a conclusion.

\section{Introduction to Pairs Trading, Operational Risk and Motivation of Study}

Pairs trading is a popular investment strategy in finance (Vidyamurthy 2004). The strategy involves taking a position in a pair of stocks that are chosen to have similar characteristics, such as the same sector category, geographic market, stock market etc. The PT is executed by taking a long position in one stock and a short position in the other stock and the PT profits from the relative differences in share price growth (or equivalently the relative firm value growth). Hence the PT method is often called a 'relative value' trading strategy (Gatev et al. 2006).

Pairs trading is a trading strategy that has a number of attractive advantages. Firstly, it is a self-financing strategy, that is the short position creates the funds for the long 
position, hence no initial capital is required to execute the trading strategy. Therefore the trade is unaffected by financing costs (such as interest rates) and leverage (or borrowing) can be applied to magnify returns. Secondly, PT provide profits that are independent of the market direction, therefore investors do not need to be good market timers (which is difficult to achieve) and can make profits during bear markets. Finally, PT have been shown to provide profits with low volatility, that is they are a source of stable profits over time, unlike other trading strategies.

The main characteristic of PT is that risk factors that are common to both firms in the pair do not affect the PT profits e.g. market risk factors (hence PT is often referred to as a 'market neutral' trading strategy (see Valle et al. 2014 for an example). This is because common factors are cancelled out from the net PT position; the common risk factor responsible for the long position's share price growth would be directly offset by the same common risk factor causing a decline in the short position.

Operational risk, essentially the risk arising from business operations within a firm, has been gaining increasing interest in literature and OMS directly impact OR. Risk can be defined as the loss associated with some statistically random event; in the case of OR the risk is the loss associated with some statistical random operational event. As risk is associated with some random event, this makes risk analysis non-trivial. A standard model of OR for financial firms is given by (Loader 2002) and is modelled by the following equation:

$$
R(A)=R_{M}(A)+R_{C}(A)+R_{O R}(A)
$$

where $R(A)$ is the total risk of company $\mathrm{A}, R_{M}(A), R_{C}(A)$ and $R_{O R}(A)$ are the market, credit and operational risk, respectively, of company A. Therefore OR is the residual risk remaining once market and credit risk are removed (Loader 2002). This model of OR captures all the wide spectrum of factors that contribute to OR (e.g. from administrative errors to natural disasters). This model of OR is also used in Mitra et al. (2015) and Allen and Bali (2007) to measure OR from stock prices.

The OR model (Loader 2002) can be applied to a pair of stocks as in a PT. If we are long stock A and short another stock B, then the overall PT position has risk:

$$
\begin{aligned}
R(A)-R(B) & =\left(R_{M}(A)+R_{C}(A)+R_{O R}(A)\right)-\left(R_{M}(B)+R_{C}(B)+R_{O R}(B)\right), \\
& =\left(R_{M}(A)-R_{M}(B)\right)+\left(R_{C}(A)-R_{C}(B)\right)+\left(R_{O R}(A)-R_{O R}(B)\right) .
\end{aligned}
$$

As mentioned previously, in PT similar stocks are chosen (i.e. same sector, market etc.), hence the market and credit risks will be similar. Consequently in a PT the $R_{M}($.) and $R_{C}($.$) terms would cancel each other out, therefore we would have:$

$$
R(A)-R(B)=R_{O R}(A)-R_{O R}(B) .
$$

Hence the net returns in a PT occur due to the difference in OR in the pair of stocks. Therefore PT profits relate to OMS performance between firms.

The fact that OR impacts PT is not an unexpected result given that it is known that operational factors impact firm value growth. In fact in Rappaport (1987) the risk or "uncertainty in business operations" (Rappaport 1987) are directly related to the firm's 
competitiveness and so profitability. Moreover, in Rappaport (1987) OR are directly related to Porter's 5 forces of competitive advantage (see Johnson et al. 2008 for more detail), hence we would expect OMS performance to be related to PT profits.

The OMS are a well established source of firm value growth (Prajogo et al. 2018) and this has been written about extensively in research literature. For example Chai et al. (2011) show increases in firm value through adopting standard OMS systems; Kohli et al. (2012) demonstrate that IT (information technology) investment significantly increases firm value. Chircu and Mahajan (2006) show that OMS impact firm value by improving operating costs and customer value. Also see Andoh-Baidoo et al. (2010), Zafar et al. (2015), Hines et al. (2004), Hsu (2013), March and Storey (2008), Pandza et al. (2003) and Bose and Leung (2013) to name a few examples.

To the best of our knowledge there is no literature on OMS performance, OR and PT (or equivalently relative firm value growth). Although, there exists extensive literature on OR and OMS (see for example Garcia-Dastugue and Lambert 2003; Hong and Lee 2013; Kim et al. 2012) the majority of studies do not focus on PT or relative firm value, but on individual firm value and on a particular OMS or OR aspects (see for instance Gillet et al. 2010; Kallenberg 2007; Allen and Bali 2007; Dahya et al. 1996). For example in Chernobai et al. (2011) the operational factors and firm value relationships are examined, however the operational factors analysed are limited to 2 factors only.

The fact that there exists little literature on the relation between OMS, OR and PT (or relative firm value) is surprising given that significant incentives exist to understand such relationships. Firms make significant investments in OMS (Yang et al. 2014) and managing OR, for example firms spend in the range of millions of dollars on OMS investments; see Renkema and Berghout (1997), Wittayasooporn et al. (2015) and Lacity and Hirschheim (2012). Furthermore, an improved understanding of OMS and OR would enable one to take more profitable trading positions in PT; this would be useful given that identifying fundamental factors in PT is non-trivial (see Vidyamurthy 2004 for more information).

A potential reason for the lack of research upon OMS, OR and PT (or relative firm value) is that firstly OMS have only recently been seen as a key resource for competitive advantage. Previously, OMS and other operational aspects were perceived as purely contributing to efficiency and production costs. However as business operations have become more sophisticated their influence on value creation has increased; see for example Shea et al. (2017), Tian et al. (2009), Ali and Green (2009), Dettenbach and Thonemann (2015), Chevalier et al. (2015), Fragnière et al. (2010) and Brandenburg et al. (2014) to name a few.

Secondly, the increasing interest in OMS, OR, the availability of operational data (Joukhadar and Rabhi 2015) and the creation of (operational) risk measurement methodologies has only occurred in the past couple of decades. For example, although models exist in other areas of risk (for instance Mitra and Date 2010; Mitra et al. 2013) models relating to quantifying OR now exist (Chorafas 2004; Loader 2002) whereas such quantitative models did not exist 25 years ago (e.g. Mitra 2013a, b). The data on operational issues (such as the type of operational incident and the losses incurred) are more easily available now and allow analysis of the direct impact of OMS upon firm value; previously such data was far less accessible. 
Thirdly, it is now recognised that managing OMS and OR are important to the profitability of firms. For example, Allied Irish Bank lost $\$ 750$ million from unauthorised trades (Cummins et al. 2006). In Biener et al. attacks on large firm IT infrastructures are cited as costing as much as \$2.4 million. In Chernobai et al. (2011) the OR in US financial institutions is examined and the median operational loss is estimated to be $\$ 11.8$ million. Moreover ORM can directly impact other important areas of business e.g. financial risk management (Zhao and Huchzermeier 2015) and market strategies (Kuthambalayan et al. 2014).

Finally, the current literature on PT typically focusses on identifying trading strategies (see for instance Huck 2010; Elliott et al. 2005; Tourin and Yan 2013). This typically involves the application of some quantitative analysis or pattern recognition method (such as neural networks), as well as modelling the entire trading strategy itself (such as entry points, exit points and stop loss limits). The current trading literature on PT also covers practical aspects of PT such as trading costs (Broussard and Vaihekoski 2012) and portfolio optimisation (Mudchanatongsuk et al. 2008). However the fundamental operational sources of PT profits (such as OMS) are not typically investigated, hence the relation of OMS to PT is not analysed.

The literature that is closest to our research is (Meng and Lee 2007); they analyse the impact on share prices due to the introduction of some IT system. The impact on firm value due to OMS is quantified, however, the OMS factors that are investigated are not operational, or specific factors (e.g. industry sector and firm size). Moreover, the firm value gains relative to another firm are not investigated, hence the relative value contribution of OMS to firms is not known. Furthermore, the degree of OR in various OMS is not analysed, hence the OMS's contribution in terms return and risk is also not analysed.

Another paper in the current literature that is closest to our research is Allen and Bali (2007). A quantitative analysis of OR and its relation to firm value is undertaken; cyclical components are detected in the OR and they discover that OR is strongly affected by catastrophic events. In Allen and Bali (2007) they also investigate key factors that impact OR however, their analysis does not relate to OMS specific factors impacting firm value and OR. For instance they analyse the relation between OR and generic risk factors such as macroeconomic and systematic factors. Hence the degree of understanding of the relation of OMS upon OR is limited, additionally no analysis of the relation with respect to relative firm value is undertaken.

The lack of literature of OMS and OR with respect to PT (or equivalently relative firm value growth) implies that their relation is not well understood. Moreover, it is also not understood the particular aspects of OMS and OR management that impact PT? For example, do OMS in particular business lines or specific operational event types have any influence on relative firm value growth? Does risk aversion of investors (that is shareholders) of operational events differ based on the event type (e.g. fraud vs. IT failure)? This therefore leads us to address the following research questions:

- To analyse the relation between PT returns and OR to determine the impact of OMS upon firm performance and relative firm value growth? 
- To analyse the relation between PT returns and OR originating from different operational events, to determine the impact of the OMS's event type upon firm performance and relative firm value growth?

- To analyse the relation between the PT returns and OR originating from different business lines, to determine the impact of the OMS's business line upon firm performance and relative firm value growth?

- To analyse the investor risk aversion and ORs by different operational factors, specifically the operational event type and business line?

\section{Methodology and Data}

In this study we analyse the impact of OMS and OR on PT returns from 11,648 pair trades, using weekly stock price data and operational event data over the period 2000-2007. In this section we explain our methodology, the experiments executed and the data sample used in our study.

\subsection{Methodology}

In this study we execute 11,648 pair trades, where each pair trade is constructed by taking a long position in one firm's shares and a short position in a similar firm's shares simultaneously; at the end of the trade we sell the long position stock and simultaneously exit the short position. We execute each PT such that we are equally weighted (or equally invested) in the long and the short position, hence the long position is funded by the short position and so we do not need to include funding costs in calculating returns.

The return from the PT position, $\mathrm{rPT}_{\mathrm{PT}}$, is calculated using Eq. (3):

$$
r_{P T}=\left(\left[\left(S_{L}(t)-S_{L}(0)\right) / S_{L}(0)\right]-\left[\left(S_{S}(t)-S_{S}(0)\right) / S_{S}(0)\right]\right) * 100
$$

where $S_{L}(t), S_{L}(0)$ are the long position stock prices at time $t$ and 0 , respectively; $S_{S}(t)$, $\mathrm{S}_{\mathrm{S}}(0)$ are the short position stock prices at time $\mathrm{t}$ and 0 , respectively.

The return in Eq. (3) is calculated using the closing prices for each stock and $t$ is set to 1 week for all trades. The trades in the same pair of stocks are conducted in non-overlapping time intervals, hence a pair in the same 2 stocks are always exited from the position before the pair are again re-entered for the next pair trade. We do not take into account any transaction costs and taxes in our trades as the purpose of the study is to analyse the relation of PT and relative firm value growth, and such costs can distort such relations.

During each PT we calculate the PT returns using Eq. (3) to obtain a distribution of PT returns, which enables us to measure the OR (see proceeding sections for more information). The distribution of PT returns are also analysed in terms of other statistical measures of interest (such as skewness and kurtosis) for additional risk analysis. We note that we construct the PT positions such that we short the firm that incurs the operational event and we are long the other stock in the pair. Consequently, the PT 
should result in a net positive return whenever an operational loss event occurs, since such an event should reduce the firm value of the shorted firm (leading to a positive return) while the other stock is unaffected.

The specific date of operational events (e.g. IT failure) were obtained from the Fitch database of operational events (from hereon OE), hence PT during and outside OE could be identified. Furthermore, the database provides details on the OE themselves, hence PT returns could be examined in terms of the origin of the OE, in particular the business line and event type, which would be required for later PT and OMS analysis.

The PT positions were chosen to be held for time intervals of 1 week to enable all operational information to be fully incorporated within the share prices (shorter time scales would not necessarily achieve this). The principle of information incorporation within stock prices is based on the Efficient Market Hypothesis (Malkiel and Fama 1970), whereby a firm's stock price fully reflects all the current information of the firm. In the context of OMS, it implies that the stock price quickly responds to new information upon the firm's OMS performance (e.g. new IT upgrade or IT error) and the firm's stock price adjusts accordingly to take into account the impact upon firm value (McWilliams and Siegel 1997). We note that the incorporation of information within stock prices is not a stringent assumption and this assumption is utilised in the methodology for analysing OR in Moosa and Silvapulle (2012).

We note in passing that the PT executed in our study are not entered or exited based on some trading rule (e.g. stock price exceeding or declining below a given price level) as in some PT methods. The PT are consistently held for the same duration of 1 week for all trades in the study, regardless of the position's profit or loss. This is because the purpose of this study is to examine the relation of PT or (relative firm value) to OMS, rather than PT trading strategies, hence results over the same time periods need to be maintained.

\subsection{Data}

The PT stocks were all chosen from the financial sector for three main reasons. Firstly, financial sector stocks tend to have high similarity in external or market factors, hence the PT is most likely to eliminate external factors from the net PT position and so provide better results with respect to OR analysis [see Eqs. (1) and (2)]. Secondly, the OMS and OR play a fundamental role in the competitive advantage of firms in the financial sector, for instance the international banking regulators Basel Committee on Banking Supervision are increasingly emphasising OR in performance issues. Hence the impact of OMS upon stock prices is more likely to be observable, rather than to be obscured by noise in the data. Thirdly, the stocks were required to be taken from the same sector to be consistent with the PT methodology (and to ensure that the stocks all have similar risk characteristics).

The PT were taken from weekly stock price data to calculate PT returns [see Eq. (3)]. The sample period for the stock data and OE data was chosen to be 2000-2007, so that no data was used prior to the Global Financial Crisis to ensure our methodology was not invalidated by the Global Financial Crisis. In our methodology we assume Eq. (2) applies to PT, since similar firms in a PT have similar credit and market risks and so 
the net risk in a PT arises from OR. However, this assumption would not necessarily have been valid during the Global Financial Crisis when unusual risk factors would distort relationships between similar stocks (see for instance Bellinia 2013; Allen et al. 2014). Hence our methodology would not necessarily lead to reliable results during the Global Financial Crisis.

The sample period was taken over 7 years so that we would have a sufficiently large sample of data points, which would provide a representative distribution of results; in total 11,648 trades were executed. A representative distribution of results was also required so that one would obtain reliable OR measurements, which are based on the result's distribution (see proceeding sections on OR measurement for more information). Furthermore the long time period also removed biases in economic growth and recessions affecting PT results.

The stocks for the PT were taken from the same sector, namely 8 different banks, giving 28 different pairs in total; we note in passing that the same number of banks were used in Moosa and Silvapulle (2012) to study OR. The stocks were also chosen on specific criteria: firstly, stocks were chosen with large market capitalisation because such stocks tend to be efficiently priced, hence their stock prices would rapidly and fully incorporate any new OE information into their stock price. Secondly, we chose stocks that had continuous stock price data during our period of study, as gaps in data would distort results. Thirdly, we chose high trading volume stocks to ensure PT results were not distorted by liquidity issues. Finally, we chose stocks with substantial OE data available (from our database) to enable sufficient operational analysis to be undertaken.

\subsection{Operational Risk Measurement}

In order to conduct our experiments we require a measure of OR. The measurement of OR is a non-trivial task because most OR measures require large amounts of data or data that is not feasible to obtain. For example, some measures require proprietary databases (Cummins et al. 2006) that are inaccessible for confidentiality reasons. Also, some OR measures require large amounts of empirical data, such that practical implementation problems arise when analysing a large number of PT.

\subsubsection{Operational Risk Measure}

Currently, there exist general OR measures with less demanding data requirements (such as the Basic Indicator Approach and Standardised Approach (Chorafas 2004), however such measures are unsuitable for our experiments. Firstly, such measures are quite broad measures of OR, in that they would not be able to attribute the risk to a particular operational event; hence the measure of OR is not specific enough for our study. Secondly, the OR measures tend to utilise data on a frequency of annual or quarterly periods, hence such measures would not be able to measure OR on a weekly basis. Given that our PT are conducted on a weekly basis, such measures would not be suitable. 
In risk measurement theory one can quantify risk associated with some risk factor by applying some appropriate statistical measure to the return distribution (Artzner et al. 1997) attributed to the risk factor; examples are quantiles (or Value at Risk) and standard deviation (Szego 2005). Consequently we can measure the OR by applying some statistical measure to the return distribution associated with OR returns:

$$
\rho=f(D)
$$

where $\rho$ is the $\mathrm{OR}, D$ is the return distribution due to $\mathrm{OR}$, and $f($.$) is some statistical$ measure applied to $D$ (e.g. quantile).

To measure the OR in PT returns we require the distribution of returns due to OR, and we then apply some risk measure to the distribution $D$ to obtain the OR, e.g. $\mathrm{VaR}$ (Value at Risk). To obtain the return distribution $D$ (from which one can obtain a measure of OR), we need to obtain returns due to OR only. This can be obtained from PT results [from Eq. (2)] where we have shown that PT returns arise from OR, hence to measure OR we apply a risk measure to the return distribution of PT returns.

The Eq. (4) has significant advantages in measuring OR compared to alternative measures. Firstly, it is a significantly more tractable method of measuring OR than competing methods; many OR measures are intractable due to substantial data requirements, calibration and implementation issues. Our method does not require substantial data, only the return distribution from OR, and no calibration or implementation issues arise other than applying a risk measure to the distribution. Secondly, we can measure OR over the short time scales required for our study ( 1 week) by obtaining $D$ for OR related weekly returns; such a property is not available with other OR measures. For example the Basic Indicator Approach and the Standardised Approach risk measures (Chorafas 2004) use data from gross income, which is typically published on an annual basis, hence OR could only be measured on an annual basis.

\subsubsection{Stock Return Components}

To analyse the PT returns we must understand the components of stock returns during an event, and this can be achieved using the Event Study method (MacKinlay 1997). The Event Study method has been utilised in many studies to determine the impact of OMS upon firm value, see for instance Agrawal et al. (2006), Dehning et al. (2003), Chatterjee et al. (2002), Benaroch et al. (2012) and Sabherwal and Sabherwal (2005) to name a few examples. It is the typical method applied in the extant literature for studies of OMS impact upon a firm (see for instance Chai et al. 2011).

The stock returns consist of 2 components according to Event Study analysis:

$$
r_{s e}=r_{e}+r_{n}
$$

where $\mathrm{r}_{s e}$ is the total stock return, $\mathrm{r}_{\mathrm{e}}$ (also known as the abnormal returns) is the stock return component due to the event itself (if an event occurs). The $r_{n}$ is defined as the normal returns, or the expected stock return when no event occurs; this can be determined by some standard model e.g. CAPM (Sharpe 1964). Hence stock returns consist of the event's return (if an event occurs) and normal stock returns, thus the 
return during an event is not equivalent to the stock returns due to an event. Hence to obtain the returns (and risk) due to the event itself we require $r_{e}$ instead of $r_{s e}$.

For PT, the previous equation becomes:

$$
r_{A L L}=r_{E}+r_{N P T}
$$

where $r_{\mathrm{ALL}}$ is the overall PT return, $\mathrm{r}_{\mathrm{NPT}}$ is the PT return when there is no operational event and $\mathrm{r}_{\mathrm{E}}$ is the PT return due to the operational event itself only (if an event occurs). For convenience we define

$$
r_{A L L}=r_{P T E} \text {, if an event occurs }
$$

where $r_{P T E}=r_{E}+r_{N P T}$ when an event occurs, and

$$
r_{A L L}=r_{N P T}, \text { if no event occurs }\left(r_{E}=0\right)
$$

As with the stock return Eq. (5), we see that PT returns during an operational event are not equivalent to the PT returns due to the operational event itself $\left(r_{E}\right)$. To obtain the OR (and returns) relating to the OE itself we require $r_{E}$ returns, hence we cannot obtain this by observing PT returns during an event (i.e. $r_{P T E}$ )—we require $r_{N P T}$ as well.

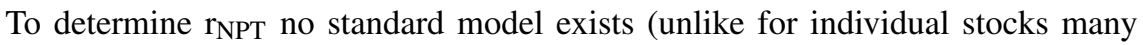
standard models exist such as CAPM). However, we can determine $\mathrm{r}_{\mathrm{NPT}}$ from empirical results by determining the PT returns when there are no events [see Eq. (8)]. This also has the advantage that we do not need to specify a particular model for normal returns, which in itself can be unreliable and problematic. We also note in passing that we cannot obtain the risk associated with $r_{E}$ by subtracting the risk difference of $r_{P T E}$ and $r_{N P T}$ because the distribution of $r_{E}$ cannot be obtained simply by subtracting or adding the distributions for $r_{P T E}$ and $r_{N P T}$ (according to standard mathematical properties of distributions).

As a side point, we expect PT to have non-zero returns even if no OE occur because we expect investors to be rewarded for bearing OR, even if no OE occur. This is directly analogous to stock returns being attributed to credit risk even if no credit event occurs, such as an announcement of default (see Allen and Bali 2007; Friewald et al. 2014 for examples).

\section{Results and Analysis}

In this section we present our results and analyse them. 


\subsection{Results}

\subsection{Analysis}

Tables 1, 2, 3, 4, 5, 6, 7, 8, 9, 10 and 11 provide the results of the PT conducted for our study. The Table 1 figures give the PT results categorised into 3 groups: the 'All' results relate to all 11,648 PT results regardless of the occurrence of any OE during a PT; the 'PTE' group relates to PT returns during OE only, and 'Event' relates to $r_{E}$ (that is PT return due to the event itself). In Table 1 the Mean row provides the mean return for each PT category over the duration of one position (i.e. 1 week) and the Annualised Mean row is the mean return converted to the annual equivalent return. It is worth noting in passing that to calculate Table 1 results for $r_{E}$ we require $r_{A L L}$ and $r_{N P T}$ [see Eq. (6)] and the mean $r_{N P T}$ return was calculated to be $-0.05 \%$ per trade.

Table 1 Returns for all pair trades $\left(r_{A L L}\right)$, pair trades during an operational event $\left(r_{P T E}\right)$, and event returns $\left(r_{E}\right)$

\begin{tabular}{llll}
\hline Return & Pair trade & & Event $\left(r_{E}\right)$ \\
\cline { 2 - 4 } & All $\left(r_{A L L}\right)$ & PTE $\left(r_{P T E}\right)^{\mathrm{a}}$ & \\
\hline Mean $(\%)$ & 0.04 & 0.12 & 0.17 \\
Annualised mean $(\%)$ & 2.28 & 6.19 & 8.79 \\
\hline
\end{tabular}

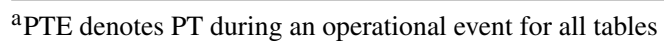

Table 2 Risk results for all pair trades $\left(r_{A L L}\right)$ and pair trades during an operational event $\left(r_{P T E}\right)$

\begin{tabular}{lrr}
\hline Risk measure & \multicolumn{1}{c}{ Pair trade } \\
\cline { 2 - 3 } & \multicolumn{1}{l}{ All } & \multicolumn{1}{c}{ PTE } \\
\hline Variance (\%) & 13.29 & 10.70 \\
VaR 99\% (\%) & -10.22 & -8.51 \\
VaR 95\% (\%) & -5.84 & -5.06 \\
VaR 90\% (\%) & -3.99 & -3.85 \\
Kurtosis & 4.25 & 1.81 \\
Skewness & -0.20 & 0.15 \\
\hline
\end{tabular}

Table 3 Risk results for events returns $\left(r_{E}\right)$

\begin{tabular}{lr}
\hline Risk measure & Result \\
\hline Variance (\%) & 10.70 \\
VaR 99\% (\%) & -8.46 \\
VaR 95\% (\%) & -5.01 \\
VaR 90\% (\%) & -3.80 \\
Kurtosis & 1.81 \\
Skewness & 0.15 \\
\hline
\end{tabular}


Table 4 Pair trade return $\left(r_{P T E}\right)$ by operational event type

\begin{tabular}{|c|c|c|c|c|c|c|c|}
\hline \multirow{2}{*}{$\begin{array}{l}\text { Pair trade } \\
\text { measure }\end{array}$} & \multicolumn{7}{|c|}{ Event type $^{\mathrm{a}}$} \\
\hline & ONB & IF & $\mathrm{EF}$ & EDPM & EPWS & DPA & CPBP \\
\hline Mean (\%) & 4.35 & -0.82 & 0.43 & 0.49 & -2.76 & 0.69 & -0.69 \\
\hline $\begin{array}{l}\text { Annualised } \\
\text { mean } \\
(\%)\end{array}$ & 226.20 & -42.64 & -22.36 & 25.48 & -143.52 & 35.88 & -35.88 \\
\hline
\end{tabular}

${ }^{\text {a }}$ See Tables 12 and 13 for abbreviations of event type and business line categories

Table 5 Operational event return $\left(r_{E}\right)$ by operational event type

\begin{tabular}{lrrrrrrr}
\hline Return & \multicolumn{7}{l}{ Event type $^{\mathrm{a}}$} \\
\cline { 2 - 7 } & ONB & IF & EF & EDPM & EPWS & DPA & CPBP \\
\hline Mean (\%) & 4.40 & -0.77 & 0.48 & 0.54 & -2.71 & 0.74 & -0.64 \\
$\begin{array}{l}\text { Annualised } \\
\text { mean } \\
(\%)\end{array}$ & 228.80 & -40.04 & 24.96 & 28.08 & -140.92 & 38.48 & -33.28 \\
& & & & & & & \\
\end{tabular}

${ }^{\text {a See Tables }} 12$ and 13 for abbreviations of event type and business line categories

Table 6 Pairs trade return $r_{P T E}$ risk results by operational event type

\begin{tabular}{|c|c|c|c|c|c|c|c|}
\hline \multirow{2}{*}{$\begin{array}{l}\text { Risk } \\
\text { measure }\end{array}$} & \multicolumn{7}{|c|}{ Event type $^{\mathrm{a}}$} \\
\hline & ONB & IF & $\mathrm{EF}$ & EDPM & EPWS & DPA & CPBP \\
\hline $\begin{array}{c}\text { Variance } \\
(\%)\end{array}$ & 7.68 & 13.91 & 13.51 & 2.33 & 20.01 & 10.81 & 6.56 \\
\hline $\begin{array}{c}\text { VaR 99\% } \\
(\%)\end{array}$ & -0.15 & -11.48 & -9.42 & -1.40 & -10.18 & -6.17 & -6.59 \\
\hline $\begin{array}{l}\text { VaR } 95 \% \\
(\%)\end{array}$ & 0.43 & -5.88 & -5.41 & -1.39 & -9.63 & -3.72 & -4.24 \\
\hline $\begin{array}{l}\text { VaR 90\% } \\
(\%)\end{array}$ & 0.87 & -5.14 & -2.78 & -0.85 & -8.95 & -2.74 & -3.43 \\
\hline Skewness & 0.23 & -0.89 & -0.36 & 1.10 & -0.84 & -0.56 & 0.41 \\
\hline Kurtosis & -0.72 & 1.58 & 1.74 & 0.59 & -0.98 & -0.29 & 2.42 \\
\hline
\end{tabular}

The OR associated with the results in Table 1 were calculated using measures such as VaR (Value at Risk) and other statistical measures and are presented in Tables 2 and 3. The Tables 2 and 3 figures are based on the weekly PT results; the 'All' results relate to the OR calculation from including all PTs. The OR for 'PTE' results are given in Table 2; the OR for $r_{E}$ results are given in Table 3. We note that the difference in Table 2 PTE results and Table 3 results can be understood from Eqs. (6) and (7). The equations imply that Table 3 results include the risk of the event itself (from the $r_{E}$ 
Table 7 Event return $r_{E}$ risk results by operational event type

\begin{tabular}{|c|c|c|c|c|c|c|c|}
\hline \multirow{2}{*}{$\begin{array}{l}\text { Risk } \\
\text { measure }\end{array}$} & \multicolumn{7}{|c|}{ Event type $^{\mathrm{a}}$} \\
\hline & ONB & IF & $\mathrm{EF}$ & EDPM & EPWS & DPA & $\mathrm{CPBP}$ \\
\hline $\begin{array}{l}\text { Variance } \\
(\%)\end{array}$ & 7.68 & 13.91 & 13.51 & 2.33 & 20.01 & 10.81 & 6.56 \\
\hline $\begin{array}{l}\mathrm{VaR} 99 \% \\
(\%)\end{array}$ & -0.10 & -11.43 & -9.37 & -1.35 & -10.13 & -6.12 & -6.54 \\
\hline $\begin{array}{l}\text { VaR } 95 \% \\
(\%)\end{array}$ & 0.48 & -5.83 & -5.36 & -1.34 & -9.58 & -3.67 & -4.19 \\
\hline $\begin{array}{l}\text { VaR } 90 \% \\
(\%)\end{array}$ & 0.92 & -5.09 & -2.73 & -0.80 & -8.90 & -2.69 & -3.38 \\
\hline Skewness & 0.23 & -0.89 & -0.36 & 1.10 & -0.84 & -0.56 & 0.41 \\
\hline Kurtosis & -0.72 & 1.58 & 1.74 & 0.59 & -0.98 & -0.29 & 2.42 \\
\hline
\end{tabular}

${ }^{\text {a See Tables }} 12$ and 13 for abbreviations of event type and business line categories

Table 8 Pairs trade return $\left(r_{P T E}\right)$ by business line

\begin{tabular}{lllllllll}
\hline Return & \multicolumn{1}{l}{ Business line $^{\mathrm{a}}$} \\
\cline { 2 - 8 } & EC & DFM & C & CT & CF & CB & AM & AONB \\
\hline $\begin{array}{c}\text { Mean } \\
(\%)\end{array}$ & -1.36 & -0.59 & 2.48 & 0.85 & 0.97 & -0.97 & 1.80 & -0.70 \\
$\begin{array}{c}\text { Annualised } \\
\text { mean } \\
(\%)\end{array}$ & -70.72 & -30.68 & 128.96 & 44.20 & 50.44 & -50.44 & 93.60 & -36.40 \\
\hline
\end{tabular}

${ }^{\text {a See Tables }} 12$ and 13 for abbreviations of event type and business line categories

Table 9 Event return $\left(r_{E}\right)$ results by business line

\begin{tabular}{lllllllll}
\hline Return & \multicolumn{7}{l}{ Business line $^{\mathrm{a}}$} \\
\cline { 2 - 8 } & EC & DFM & C & CT & CF & CB & AM & AONB \\
\hline $\begin{array}{c}\text { Mean } \\
(\%)\end{array}$ & -1.34 & -0.54 & 2.53 & 0.90 & 1.03 & -0.92 & 1.85 & -0.65 \\
$\begin{array}{c}\text { Annualised } \\
\text { mean } \\
(\%)\end{array}$ & -69.68 & -28.08 & 131.56 & 46.8 & 53.56 & -47.84 & 96.2 & -33.8 \\
\hline
\end{tabular}

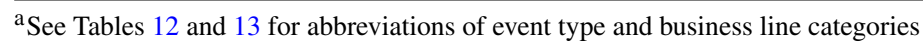

term), whereas Table 2 PTE results include the risk of the event itself and the OR in the firm when there is no OE.

The PTE results of Table 1 are analysed further by OE type and business line in Tables 4 and 8, respectively; the PTE results of Table 2 are also analysed further by OE type and business line in Tables 6 and 10, respectively. Similarly, for the $r_{E}$ results in Table 1, the results are also analysed further by OE type and business line in Tables 5 and 9, respectively; the Table 3 results are also analysed further by OE type and 
Table 10 Pairs trade $r_{P T E}$ risk results by business line

\begin{tabular}{|c|c|c|c|c|c|c|c|c|}
\hline \multirow{2}{*}{$\begin{array}{l}\text { Risk } \\
\text { measure }\end{array}$} & \multicolumn{8}{|c|}{ Business line $\mathrm{e}^{\mathrm{a}}$} \\
\hline & $\mathrm{EC}$ & DFM & $\mathrm{C}$ & $\mathrm{CT}$ & $\mathrm{CF}$ & $\mathrm{CB}$ & AM & AONB \\
\hline $\begin{array}{l}\text { Variance } \\
(\%)\end{array}$ & 1.83 & 2.90 & 25.21 & 1.22 & 3.95 & 9.12 & 6.43 & 6.54 \\
\hline $\begin{array}{l}\text { VaR 99\% } \\
(\%)\end{array}$ & -3.78 & -3.17 & -3.95 & -1.15 & -3.36 & -8.33 & -3.92 & -6.05 \\
\hline $\begin{array}{l}\text { VaR } 95 \% \\
(\%)\end{array}$ & -3.27 & -3.07 & -3.73 & -0.81 & -2.20 & -5.37 & -1.69 & -5.04 \\
\hline $\begin{array}{l}\text { VaR } 90 \% \\
(\%)\end{array}$ & -2.75 & -2.93 & -3.49 & -0.37 & -1.04 & -4.75 & 0.18 & -4.24 \\
\hline Skewness & 0.22 & 0.50 & 0.03 & 0.07 & -0.31 & -0.23 & -0.97 & -1.01 \\
\hline Kurtosis & 0.98 & 0.69 & -1.25 & 0.52 & 0.37 & 0.53 & 2.49 & 0.13 \\
\hline
\end{tabular}

${ }^{\text {a See Tables }} 12$ and 13 for abbreviations of event type and business line categories

Table 11 Event return $r_{E}$ risk results by business line

\begin{tabular}{|c|c|c|c|c|c|c|c|c|}
\hline \multirow{2}{*}{$\begin{array}{l}\text { Risk } \\
\text { measure }\end{array}$} & \multicolumn{8}{|c|}{ Business line $\mathrm{e}^{\mathrm{a}}$} \\
\hline & $\mathrm{EC}$ & DFM & $\mathrm{C}$ & CT & $\mathrm{CF}$ & $\mathrm{CB}$ & $\mathrm{AM}$ & AONB \\
\hline $\begin{array}{c}\text { Variance } \\
(\%)\end{array}$ & 1.85 & 2.90 & 25.21 & 1.22 & 4.15 & 9.12 & 6.43 & 6.54 \\
\hline $\begin{array}{l}\text { VaR } 99 \% \\
(\%)\end{array}$ & -3.77 & -3.12 & -3.90 & -1.10 & -3.33 & -8.28 & -3.87 & -6.00 \\
\hline $\begin{array}{l}\text { VaR } 95 \% \\
(\%)\end{array}$ & -3.26 & -3.02 & -3.68 & -0.76 & -2.21 & -5.32 & -1.64 & -4.99 \\
\hline $\begin{array}{l}\text { VaR } 90 \% \\
(\%)\end{array}$ & -2.74 & -2.88 & -3.44 & -0.32 & -1.01 & -4.70 & 0.23 & -4.19 \\
\hline Skewness & 0.25 & 0.50 & 0.03 & 0.07 & -0.32 & -0.23 & -0.97 & -1.01 \\
\hline Kurtosis & 1.03 & 0.69 & -1.25 & 0.52 & 0.22 & 0.53 & 2.49 & 0.13 \\
\hline
\end{tabular}

${ }^{\text {a See Tables }} 12$ and 13 for abbreviations of event type and business line categories

Table 12 Categories for operational event types and abbreviations

\begin{tabular}{ll}
\hline Abbreviation & Event type \\
\hline CPBP & Clients products and business practices \\
DPA & Damage to physical assets \\
EDPM & Execution delivery and process management \\
EF & External fraud \\
EPWS & Employment/workplace practices \\
IF & Internal fraud \\
ONB & Other operational events \\
\hline
\end{tabular}


Table 13 Categories for business lines and abbreviations

\begin{tabular}{ll}
\hline Abbreviation & Business line \\
\hline AONB & All other business lines \\
AM & Asset management \\
C & Custody \\
CB & Commercial banking \\
CF & Corporate finance \\
CT & corporate trust \\
DFM & Discretionary fund management \\
EC & External clients \\
\hline
\end{tabular}

business line in Tables 7 and 11, respectively. The table categories and abbreviations are given in Tables 12 and 13 .

In Table 1, the mean returns for different PT groups are presented. The returns vary substantially by group: the mean PT returns are 2.28\%/year for All trades, 6.19\%/year for PTE and $8.79 \%$ p.a. (per annum) for $r_{E}$. Hence PT returns more than double during OE and the OE's return itself accounts for almost 3 times the mean PT return during All trades. Additionally, the $8.79 \%$ p.a. return in itself is a high annual growth contribution to firm value, given that this is almost equal to the average annual return on the stockmarket.

The results of Table 1 demonstrates that PT profits are strongly related to OMS performance and OR management (from hereon ORM), hence OMS contribution to firm value growth is significant. As mentioned in the literature discussed in the earlier sections, operational issues were not previously considered critical aspects of firm performance until recent decades, and our results demonstrate that such factors are core elements of a firm's performance. Additionally, the high returns from $r_{E}$ also demonstrate that firms can improve their relative performance compared to their rivals by investing in their OMS and ORM.

In Tables 2 and 3, the OR is measured by applying some statistical measure to the PT returns (as explained in the previous sections). The OR associated with the OMS is important to quantify in order to determine the quality of the contribution of OMS to firm value. This is because firms are not just interested in the firm value contribution from OMS (or any investment) but also the risk incurred (see for instance Volkov and Smith 2014; Brown et al. 2012). In fact many operations can be typically improved to increase firm value but they incur higher OR and so are not implemented. For example, one could reduce fraud checks to reduce business costs (and so improve firm value) but this would be at the expense of increasing the risk of fraud. Hence we need to determine the quality of OMS contributions to firm value by taking into account the associated OR.

The Table 2 results have significant implications. Firstly, in Table 2 we notice that OR is significant in magnitude, for example, for All trades at the VaR 99\% level we have $-10.22 \%$ over a period of 1 week; given that the average annual return on stock market indexes is approximately $10 \%$ p.a., a $-10.22 \%$ loss can therefore eliminate a firm's average annual share price growth in just 1 week. Secondly, the magnitude 
of the losses or risk values in Table 2 imply that $\mathrm{OR}$ is not a negligible risk and that ORM is an important factor in firm risk. This can be attributed to operations becoming increasingly important to firm performance (e.g. IT systems).

Thirdly, if we analyse Tables 1 and 2 in terms of return to risk, as is done in Basu and Nair (2015), by computing a ratio similar to the Sharpe ratio in investment we obtain interesting results. The PTE results provide far higher returns for a given level of risk compared to All trades. This implies that return-to-risk in non-OE focussed OMS and ORM investments will not return as much to firm value as OE focussed OMS and ORM investments. This may also justify the high investment made in particular OMS (see for instance (Lacity and Hirschheim 2012).

We notice in Table 2 that the difference in risk between All trades and PTE is approximately $10 \%$. Given that All trade returns (and therefore risks) include returns during OEs and not during OEs [see Eq. (6)], this implies that the majority of PT returns and risks arise during OEs. If we examine Table 2 PTE results further, we can see that the results are the same or higher risk than the results in Table 3 on all risk measures (this is an expected result because the returns (and therefore the risk) of PTE include $r_{E}$, therefore PTE's OR will always be greater than or equal to the OR of the OE itself). The difference in Table 3 and Table 2 PTE results is approximately a $10-20 \%$ decrease in value, hence the key source of OR during an OE is due to the event itself. This is useful for ORM because it implies firms can strategically improve ORM by focussing on OE based risks, rather than risks that do not cause any significant events.

The kurtosis results for Table 2 differ between All trades and PTE, however PTE and Table 3 results are identical, which imply that kurtosis risk does not differ for all ORs during an OE. This is useful to know for ORM as it means kurtosis risk will not impact operations differently (for instance underestimation of particular risks), hence this facilitates risk management of operations. In Table 2 the skewness values of PTE and All trades are close to 0 , therefore both distributions are fairly symmetric. Hence skewness risk (which can lead to underestimating OR) is not a significant factor for OR. We note that the positive skewness in PTE implies the PTE distribution is shifted more towards negative values, whereas the All trades distribution is shifted towards positive values.

Within Table 2 the All trade kurtosis is more than double that of PTE's kurtosis; given that the All trade distribution consists of the PTE and non-PTE distributions, this implies the non-PTE distribution kurtosis must be lower than the PTE distribution kurtosis. The consequence of lower kurtosis mean that non-PTE returns tend to concentrate more around the mean, and so are more predictable in value. However, PTE returns are more unpredictable, implying that $\mathrm{OE}$ lead to more unpredictable changes in firm value; this is to be expected because OE can have a varying impact on firms due their nature. For example, a simple I.T. error that incorrectly reports a number can lead to minor or major losses. The greater variation in PTE returns highlights the importance to manage ORs effectively to minimise losses.

Tables 4 and 6 break down the PTE results by event type in terms of returns and risk respectively; similarly Tables 5 and 7 break down the $r_{E}$ results by events type in terms of returns and risk respectively. If we compare the values of Tables 4 and 5, both are very similar with little difference in value, implying the majority of stock returns during 
an $\mathrm{OE}$ is due to the event itself. However, the magnitude of the returns in Tables 4 and 5 demonstrate the importance of operational factors and OMS in relative firm value growth; given that the average return on the stock market is approximately $10 \%$ p.a. the annualised returns demonstrate the considerably large changes that occur through OMS and ORM. A similar pattern is reflected between Tables 6 and 7, implying that the majority of OR during an OE is due to the event's OR itself.

In Tables 4 and 5 an important observation is obtained in that there is significant variation in return and risk dependent on the event type: ONB has the highest return $(4.35 \%)$ whilst EPWS has the lowest $(-2.76 \%)$, with the average of the PT returns at $0.12 \%$. In all cases the returns represent significant changes on an annualised basis (as shown in Table 4) and so imply a significant dependence between operational factors and PT returns. Hence relative firm value growth and competitive advantage is significantly influenced by the type of OE. Hence firms can improve firm value and relative firm value growth further by focussing on particular operational issues, rather than managing all operational issues with equal importance.

Similar to Tables 4 and 5, in Tables 6 and 7 we observe there is significant variation in OR by event type, hence OR is significantly dependent on the event type. Intuitively, we would expect OR variation upon the event type itself (e.g. the risk associated with fraud would be significantly higher than the risk of administration errors). Additionally the degree of variation in OR is an unexpected result, for example EPWS has almost 9 times the risk of EDPM on a variance risk measure basis; the risk of all PTE trades is 10.70 on a variance risk measure basis (from Table 2), while EDPM has almost one fifth of this risk (2.33) and EPWS has almost double this level of risk (20.01). Consequently, these results also reinforce the importance of strategic or focussed ORM to minimise overall OR.

On a relative firm value basis, Tables 4 and 6 provide interesting results. If one takes the Sharpe ratio equivalent or return to risk ratio (by using Table 4 and the variance figures in Table 6), ONB has the highest Sharpe ratio (due to one of the lower OR figures and the highest mean returns), EPWS has the lowest Sharpe ratio (due to its low mean return and high risk). Thus, although EPWS is high risk it does not lead to significant losses on a loss per risk basis, in other words reducing risk on EPWS would not be as beneficial as reducing ONB risk. Hence in order to take into account OR and firm value, firms should also manage OR strategically, in this case it would be better for OMS to target ONB rather than EPWS events.

In Table 6 there exist wide variation in skewness and kurtosis values; in Table 2 they are only positive whereas in Table 6 there are positive and negative values (for skewness from -0.89 to 1.1 and for kurtosis -0.98 to 2.42 ). We notice that ONB, EDPM and CPBP are right skewed distributions giving more positive PT returns, whereas IF, EF, EPWS and DPA are negatively skewed and so have more negative PT returns. Similarly, IF, EF, EDPM, CPBP have positive kurtosis giving more peaked distributions around the mean for PT returns, whereas ONB, EPWS, DPA have negative kurtosis and so have less peaked distributions.

The wide variation in kurtosis and skewness in Table 6 compared to Table 2 has implications for ORM and OMS. The variation in skewness and kurtosis implies that under or over-estimation of risk can vary significantly depending on the OE. Therefore to manage OR more strategically (that is to focus on specific OR types) also 
must involve careful risk estimation to prevent skewness and kurtosis risks impacting ORM, which in turn impacts OMS.

Tables 8 and 9 give the PT results by business lines during OE. We observe that the magnitude of the returns are significant along all business lines, hence OMS and ORM play an important role in all business lines in contributing to relative firm value and risk management. We expect all OMS and ORM to have a significant impact across all business lines because OMS play a critical role across all areas of the entire firm nowadays.

In Tables 8 and 9 it can be seen there is significant variation in values depending on each business line; for example we notice that $\mathrm{C}$ has the highest PT return $(2.48 \%)$, while EC has the lowest return (-1.36\%). This implies that OMS and ORM impact on relative firm value growth and risk management is substantially influenced by business line. Consequently, OMS and ORM need to be strategically resourced and allocated along particular business lines, and not just take into account OE types, to maximise their impact on firms. We note that we would expect significant variations in results across business lines (from hereon BL) because different BLs have differing levels of exposure to operational losses and risks.

From Table 8 we observe that the variation in mean PT returns is lower between business lines $(3.84 \%)$, compared to the variation in OEs in Table $3(7.11 \%)$ - the difference is almost half. Hence although BL affect relative firm value losses, the variation in such losses is more dependent on OE type. Consequently OMS and ORM resource allocation should carefully take into account the OE type rather than the BL to maximise their impact on firm value.

In Table 8 we calculate the Sharpe ratios on BLs using Table 10, to provide information on the risk management of OR. We observe that EC has the lowest Sharpe ratio of -1.49 due to its low mean return, while AM has the highest ratio of 0.45 due to its high mean return (even though its variance is quite high). Thus although AM may not be the highest risk BL, it would lead to the greatest firm value loss for each unit of risk (on a variance risk measure basis). This supports the need for strategic or focussed resourcing of OMS and ORM as it would be better to reduce the AM BL risk in terms risk reduction per firm value loss, rather than any other BL.

In Table 10 the most riskiest BL is $\mathrm{C}$ on all risk measures, however the least riskiest $\mathrm{BL}$ is somewhat unclear to discern as it is dependent on the risk measure; it is EC using $\mathrm{VaR}$ (at all quantiles) or CT using variance. In Table 11 we observe that the results obtained are similar in value and pattern to Table 10 with respect to risk, skewness and kurtosis; in fact the difference in all values between Tables 10 and 11 is approximately $1 \%$. This implies that practically all the OR arises from the event itself during an OE, even when results are analysed along BLs. Hence our results are consistent with OE results discussed previously in Tables 6 and 7.

In Table 10 we notice that there is significant variation in OR between BLs and the variation in OR is greater than in Table 6; for instance the variance of $\mathrm{C}(25.21 \%)$ is approximately 21 times greater than that of CT (1.22\%). Hence the variation of OR is significantly more dependent on BL than event type. This result is important for OMS and ORM implementation because it implies some BLs should be managed more carefully than others to reduce overall firm risk. 
In Table 10 the skewness of BLs varies between -1.01 (for AONB) to 0.50 (for DFM), which is less than the variation in skewness for OEs (from -0.89 to 1.10). Hence skewness risk is less significant in BLs than in OEs, hence this risk does not need to be addressed as much in ORM and OMS for BLs. The kurtosis of BLs varies from -1.25 (for C) to 2.49 (for AM) and so is considerably more than in OEs (which is from -0.98 to 2.42 ). Additionally, the kurtosis is positive for all BLs except $\mathrm{C}$, whereas 3 of the 7 categories in Table 6 are negative. This suggests that negative kurtosis is more dependent on the $\mathrm{OE}$ rather than the $\mathrm{BL}$, which is useful information in managing kurtosis risk for OMS and ORM.

The Sharpe ratios calculated can also be used to determine investor risk aversion, in that investor risk aversion increases with the Sharpe ratio (Bodie et al. 2002). The risk aversion of individuals has important implications for risk management and OR (see Chen et al. 2007; Wang and Hsu 2009 for examples). The differing investor risk aversions are also important for managers to understand, so that managers can address investor perceived risks. This is because investors' wealth management and views are becoming increasing important, for instance value-based management (Hahn and Kuhn 2012) is becoming more popular. From a relative firm value perspective, it is important to be aware of differing investor risk aversion to ensure the share prices are not disproportionately affect by any ORs and OEs.

The differing Sharpe ratio values for the results reflect the differing investor risk aversions associated with different event types and BLs. In other words, our results imply investors are more risk averse to some operational factors than others, based on the event type or BL. In terms of event type, EPWS has the lowest investor risk aversion, whilst ONB has the highest risk aversion. This means that investors perceive EPWS related issues with less risk, perhaps because EPWS risks are easier to understand than ONB which could arise from any OR. In terms of OMS and ORM it would suggest that fewer resources should be allocated to EPWS issues, and this would possibly explain the reason that firms invest more in other areas for OMS and ORM.

In terms of BLs, the EC has the lowest investor risk aversion while AM has the highest risk aversion. We may expect the AM BL to be perceived as the highest risk BL because this $\mathrm{BL}$ tends to be exposed to large funds and has been subject to large operational losses in the past. Similarly, EC has not been exposed to as many operational losses in the past and so may be perceived by investors as a lower OR area. Again, this may account for higher investment in OMS and ORM in AM BLs compared to other BLs.

The issue of investor risk perception has important implications for ORM in that risk communication is becoming an increasingly important part of risk management; in fact Kallenberg (2007) concludes that risk communication is a more significant factor in firm value loss rather than the operational loss itself. Our results therefore imply that ORM and OMS need to be communicated on a strategic basis to reduce firm value loss, that is risk communications of OEs in particular BLs and OE need to be managed more effectively to reduce firm value losses. 


\section{Conclusion}

In this paper we investigated the relation between relative firm, PT, OMS and ORM. Firstly, we showed that relative operational performance between firms can be evaluated from pair trade returns, providing a new method of measuring operational performance. This was substantiated by empirical results that show that significant PT returns occur during operational events only. In our paper we investigated 11,648 PT, using weekly stock price data, OE data, and analysed the impact on relative firm value growth, OR, OMS and ORM. We have found that profitable PT returns are mainly accounted by the occurrence of OE, highlighting the importance of OMS and ORM to relative firm value growth and performance. We have also shown that $\mathrm{OE}$ result in significant relative firm value growth, and so highlight the importance of OR as a significant risk factor to firms.

We have found that PT returns, and therefore OMS and ORM performance, is significantly impacted by the type of OE and the BL, implying that firm performance and risk management can be improved by strategically re-allocating resources. In other words, OMS and ORM resources should focus on particular OE and BL that cause greater firm losses and risks. Our results also show that OR return to risk ratios, OE losses and ORs themselves all vary by BL and OE type, hence OMS and ORM need to take into account all operational factors in order to appropriately manage operations.

Our results show that investor risk aversion varies by BL and event type and hence this needs to be taken into account in organising OMS and ORM to reduce firm value losses. Moreover, the issue of investor risk perception has important implications for ORM in terms of risk communication, which is becoming an increasingly important part of risk management. In fact Kallenberg (2007) concludes that risk communication is more important to firm value losses than the event itself.

Our paper is the first to provide a trading application of OR, in that it can be shown to demonstrate the role of OR and OE in profitable PT, whereas the majority of literature on OR is focussed on risk measurement and management. Moreover, our paper provides an alternative explanation of PT profits compared to current explanations. For example, current explanations of PTs include market inefficiencies whereas we have demonstrated that PT profits arise from operational factors.

In terms of future directions of work, one should investigate additional factors that may influence OR and PT returns, such as industry based factors. Also, there should be further development of risk factor models to incorporate operational factors (such as business line and event type) to determine the impact of such factors on firms, which is currently missing in most models. Finally, there should be investigations into potential methods of hedging OR, such as developing new hedging models, derivative models or other hedging instruments, as this is currently not possible with any financial instrument and OR represents an important risk factor to firms.

Open Access This article is distributed under the terms of the Creative Commons Attribution 4.0 International License (http://creativecommons.org/licenses/by/4.0/), which permits unrestricted use, distribution, and reproduction in any medium, provided you give appropriate credit to the original author(s) and the source, provide a link to the Creative Commons license, and indicate if changes were made. 


\section{References}

Agrawal, M., Kishore, R., \& Rao, H. R. (2006). Market reactions to e-business outsourcing announcements: An event study. Information \& Management, 43(7), 861-873.

Ali, S., \& Green, P. (2009). Effective information technology (IT) governance mechanisms: An IT outsourcing perspective. Information Systems Frontiers, 14(2), 179-193.

Allen, L., \& Bali, T. (2007). Cyclicality in catastrophic and operational risk measurements. Journal of Banking \& Finance, 31, 1191-1235.

Allen, D. E., Powell, R. J., \& Singh, A. K. (2014). Take it to the limit: Innovative CVaR applications to extreme credit risk measurement. European Journal of Operational Research, 249(2), 465-475.

Andoh-Baidoo, F. K., Osei-Bryson, K., \& Amoako-Gyampah, K. (2010). Effects of firm and IT characteristics on the value of e-commerce initiatives: An inductive theoretical framework. Information Systems Frontiers, 14(2), 237-259.

Artzner, P., Delbaen, F., Eber, J. M., \& Heath, D. (1997). Thinking coherently. Risk, 10(11), 68-71.

Basu, P., \& Nair, S. K. (2015). Analyzing operational risk-reward trade-offs for start-ups. European Journal of Operational Research, 247(2), 596-609.

Bellinia, T. (2013). Integrated bank risk modeling: A bottom-up statistical framework. European Journal of Operational Research, 230, 385-398.

Benaroch, M., Chernobai, A., \& Goldstein, J. (2012). An internal control perspective on the market value consequences of it operational risk events. International Journal of Accounting Information Systems, 13, 357-381.

Bodie, Z., Kane, A., \& Marcus, A. J. (2002). Investments.

Bose, I., \& Leung, A. C. M. (2013). The impact of adoption of identity theft countermeasures on firm value. Decision Support Systems, 55(3), 753-763.

Brandenburg, M., Govindan, K., Sarkis, J., \& Seuring, S. (2014). Quantitative models for sustainable supply chain management: Developments and directions. European Journal of Operational Research, 233(2), 299-312.

Broussard, J. B., \& Vaihekoski, M. (2012). Profitability of pairs trading strategy in an illiquid market with multiple share classes. Journal of International Financial Markets, Institutions and Money, 22(5), 1188-1201.

Brown, S., Goetzmann, W., Liang, B., \& Schwarz, C. (2012). Trust and delegation. Journal of Financial Economics, 103(2), 221-234.

Chai, S., Kim, M., \& Rao, H. R. (2011). Firms' information security investment decisions: Stock market evidence of investors' behavior. Decision Support Systems, 50(4), 651-661.

Chatterjee, D., Pacini, C., \& Sambamurthy, V. (2002). The shareholder-wealth and trading-volume effects of information-technology infrastructure investments. Journal of Management Information Systems, 19(2), 7-42.

Chen, X., Sim, M., Simchi-Levi, D., \& Sun, P. (2007). Risk aversion in inventory management. Operations Research, 55(5), 828-842.

Chernobai, A., Jorion, P., \& Yu, F. (2011). The determinants of operational risk in US financial institutions. Journal of Financial and Quantitative Analysis, 46(6), 1683.

Chevalier, P., Lamas, A., Lu, L., \& Mlinar, T. (2015). Revenue management for operations with urgent orders. European Journal of Operational Research, 240(2), 476-487.

Chircu, A. M., \& Mahajan, V. (2006). Managing electronic commerce retail transaction costs for customer value. Decision Support Systems, 42(2), 898-914.

Chorafas, D. (2004). Operational risk control with Basel II: Basic principles and capital requirements. Oxford: Butterworth-Heinemann.

Cummins, J., Lewis, C., \& Wei, R. (2006). The market value impact of operational loss events for us banks and insurers. Journal of Banking \& Finance, 30, 2605-2634.

Dahya, J., Lonie, A. A., \& Power, D. M. (1996). The case for separating the roles of chairman and CEO: An analysis of stock market and accounting data. Corporate Governance: An International Review, 4(2), 71-77.

Dehning, B., Richardson, V. J., \& Zmud, R. W. (2003). The value relevance of announcements of transformational information technology investments. MIS Quarterly, 27(4), 637-656.

Dettenbach, M., \& Thonemann, U. W. (2015). The value of real time yield information in multi-stage inventory systems-Exact and heuristic approaches. European Journal of Operational Research, 240(1), $72-83$. 
Dey, P. K. (2004). Analytic hierarchy process helps evaluate project in Indian oil pipelines industry. International Journal of Operations \& Production Management, 24(6), 588-604.

Dos Santos, B. L., Peffers, K., \& Mauer, D. C. (1993). The impact of information technology investment announcements on the market value of the firm. Information Systems Research, 4(1), 1-23.

Elliott, R. J., Van Der Hoek, J., \& Malcolm, W. P. (2005). Pairs trading. Quantitative Finance, 5(3), 271-276.

Fragnière, E., Gondzio, J., \& Yang, X. (2010). Operations risk management by optimally planning the qualified workforce capacity. European Journal of Operational Research, 202(2), 518-527.

Friewald, N., Wagner, C., \& Zechner, J. (2014). The cross-section of credit risk premia and equity returns. The Journal of Finance, 69(6), 2419-2469.

Garcia-Dastugue, S. J., \& Lambert, D. M. (2003). Internet-enabled coordination in the supply chain. Industrial Marketing Management, 32, 251-263.

Gatev, E., Goetzmann, W. N., \& Rouwenhorst, K. G. (2006). Pairs trading: Performance of a relative-value arbitrage rule. Review of Financial Studies, 19(3), 797-827.

Gillet, R., Hübner, G., \& Plunus, S. (2010). Operational risk and reputation in the financial industry. Journal of Banking \& Finance, 34(1), 224-235.

Hahn, G. J., \& Kuhn, H. (2012). Designing decision support systems for value-based management: A survey and an architecture. Decision Support Systems, 53, 591-598.

Hines, Peter, Holweg, Matthias, \& Rich, Nick. (2004). Learning to evolve. International Journal of Operations \& Production Management, 24(10), 994-1011.

Hong, Z., \& Lee, C. (2013). A decision support system for procurement risk management in the presence of spot market. Decision Support Systems, 55, 67-78.

Hora, M., \& Klassen, R. D. (2013). Learning from others' misfortune: Factors influencing knowledge acquisition to reduce operational risk. Journal of Operations Management, 31(1), 52-61.

Hsu, P. F. (2013). Integrating ERP and e-business: Resource complementarity in business value creation. Decision Support Systems, 56, 334-347.

Huck, N. (2010). Pairs trading and outranking: The multi-step-ahead forecasting case. European Journal of Operational Research, 207(3), 1702-1716.

Im, K. S., Dow, K. E., \& Grover, V. (2001). Research report: A reexamination of IT investment and the market value of the firm-An event study methodology. Information Systems Research, 12(1), 103-117.

Jiang, B., Frazier, G. V., \& Prater, E. L. (2006). Outsourcing effects on firms operational performance. International Journal of Operations \& Production Management, 26(12), 1280-1300.

Johnson, G., Scholes, K., \& Whittington, R. (2008). Exploring corporate strategy: Text and cases. London: Pearson Education.

Joukhadar, G., \& Rabhi, F. (2015). SOA in practice-A study of governance aspects. Information Systems Frontiers, 18(3), 499-510.

Kallenberg, K. (2007). The role of risk in corporate value: A case study of the ABB asbestos litigation. Journal of Risk Research, 10(8), 1007-1025.

Kim, J. Y., Altinkemer, K., \& Bisi, A. (2012). Yield management of workforce for it service providers. Decision Support Systems, 53, 23-33.

Kohli, R., Sarv, D., \& Terence, T. O. (2012). Does information technology investment influence a firm's market value? A case of non-publicly traded healthcare firms. MIS Quarterly, 36(4), 1145-1163.

Kuthambalayan, T. S., Mehta, P., \& Shanker, K. (2014). Integrating operations and marketing decisions using delayed differentiation of products and guaranteed delivery time under stochastic demand. European Journal of Operational Research, 237(2), 617-627.

Lacity, M. C., \& Hirschheim, R. (2012). The information systems outsourcing bandwagon. Sloan Management Review, 34 .

Loader, D. (2002). Controls, procedures and risk. Oxford: Butterworth-Heinemann.

MacKinlay, A. C. (1997). Event studies in economics and finance. Journal of Economic Literature, 35 , 13-39.

Malkiel, B. G., \& Fama, E. F. (1970). Efficient capital markets: A review of theory and empirical work. The Journal of Finance, 25(2), 383-417.

March, S. T., \& Storey, V. C. (2008). Design science in the information systems discipline: An introduction to the special issue on design science research. Management Information Systems Quarterly, 32(4), 6.

Martinsons, M., Davison, R., \& Tse, D. (1999). The balanced scorecard: A foundation for the strategic management of information systems. Decision Support Systems, 25(1), 71-88.

McWilliams, A., \& Siegel, D. (1997). Event studies in management research: Theoretical and empirical issues. Academy of Management Journal, 40(3), 626-657. 
Meng, Z., \& Lee, S. Y. T. (2007). The value of IT to firms in a developing country in the catch-up process: An empirical comparison of China and the United States. Decision Support Systems, 43(3), 737-745.

Mitra, S. (2013a). Operational risk of option hedging. Economic Modelling, 33, 194-203.

Mitra, S. (2013b). Scenario generation for operational risk. Intelligent Systems in Accounting, Finance and Management, 20, 163-187.

Mitra, S., \& Date, P. (2010). Regime switching volatility calibration by the Baum-Welch method. Journal of Computational and Applied Mathematics, 234(12), 3243-3260.

Mitra, S., Date, P., Mamon, R., \& Wang, I. C. (2013). Pricing and risk management of interest rate swaps. European Journal of Operational Research, 228(1), 102-111.

Mitra, S., Karathanasopoulos, A., Sermpinis, G., Dunis, C., \& Hood, J. (2015). Operational risk: Emerging markets, sectors and measurement. European Journal of Operational Research, 241(1), 122-132.

Moormann, J., \& Lochte-Holtgreven, M. (1993). An approach for an integrated DSS for strategic planning. Decision Support Systems, 10(4), 401-411.

Moosa, I., \& Silvapulle, P. (2012). An empirical analysis of the operational losses of Australian banks. Accounting \& Finance, 52(1), 165-185.

Mudchanatongsuk, S., Primbs, J. A., \& Wong, W. (2008). Optimal pairs trading: A stochastic control approach. In American control conference, 2008. IEEE.

Mukhopadhyay, A., Chatterjee, S., Bagchi, K. K., Kirs, P. J., \& Shukla, G. K. (2017). Cyber risk assessment and mitigation (CRAM) framework using logit and probit models for cyber insurance. Information Systems Frontiers. https://doi.org/10.1007/s10796-017-9808-5.

Pandza, K., Horsburgh, S., Gorton, K., \& Polajnar, A. (2003). A real options approach to managing resources and capabilities. International Journal of Operations \& Production Management, 23, no, 9.

Papazafeiropoulou, A., \& Spanaki, K. (2015). Understanding governance, risk and compliance information systems (GRC IS): The experts view. Information Systems Frontiers, 18(6), 1251-1263.

Prajogo, D., Toy, J., Bhattacharya, A., Oke, A., \& Cheng, T. (2018). The relationships between information management, process management and operational performance: Internal and external contexts. International Journal of Production Economics, 199, 95-103.

Rappaport, A. (1987). Linking competitive strategy and shareholder value analysis. Journal of Business Strategy, 7(4), 58-67.

Reim, W., Parida, V., \& Sjödin, D. R. (2016). Risk management for product-service system operation. International Journal of Operations \& Production Management, 36(6), 665-686.

Renkema, T. J., \& Berghout, E. W. (1997). Methodologies for information systems investment evaluation at the proposal stage: A comparative review. Information and Software Technology, 39(1), 1-13.

Sabherwal, R., \& Sabherwal, S. (2005). Knowledge management using information technology: Determinants of short-term impact on firm value. Decision Sciences, 36(4), 531-567.

Scott, S., \& Perry, N. (2009). The enactment of risk categories: The role of information systems in organizing and re-organizing risk management practices in the energy industry. Information Systems Frontiers, 14(2), 125-141.

Sharpe, W. F. (1964). Capital asset prices: A theory of market equilibrium under conditions of risk. The Journal of Finance, 19(3), 425-442.

Shea, V. J., Dow, K. E., Chong, A. Y.-L., \& Ngai, E. W. T. (2017). An examination of the long-term business value of investments in information technology. Information Systems Frontiers. https://doi.org/10. 1007/s10796-017-9735-5.

Sillince, J. A. A., \& Sykes, G. M. H. (1993). Integrating MRPII and JIT: A management rather than a technical challenge. International Journal of Operations \& Production Management, 13(4), 18-31.

Silvestro, R., \& Lustrato, P. (2014). Integrating financial and physical supply chains: The role of banks in enabling supply chain integration. International Journal of Operations \& Production Management, 34(3), 298-324.

Szego, G. (2005). Measures of risk. European Journal of Operational Research, 163, 5-19.

Tazelaar, F., \& Snijders, C. (2013). Operational risk assessments by supply chain professionals: Process and performance. Journal of Operations Management, 31(1), 37-51.

Tian, J., Wang, K., Chen, Y., \& Johansson, B. (2009). From IT deployment capabilities to competitive advantage: An exploratory study in China. Information Systems Frontiers, 12(3), 239-255.

Tourin, A., \& Yan, R. (2013). Dynamic pairs trading using the stochastic control approach. Journal of Economic Dynamics and Control, 37, 1972-1981. 
Ülengin, F., Önsel, Ş., Aktas, E., Kabak, Ö., \& Özaydın, Ö. (2014). A decision support methodology to enhance the competitiveness of the Turkish automotive industry. European Journal of Operational Research, 234(3), 789-801.

Valle, C. A., Meade, N., \& Beasley, J. E. (2014). Market neutral portfolios. Optimization Letters, 8, 1961. https://doi.org/10.1007/s11590-013-0714-6.

Vidyamurthy, G. (2004). Pairs Trading: Quantitative methods and analysis (Vol. 217). Hoboken: Wiley.

Volkov, N. I., \& Smith, G. C. (2014). Corporate diversification and firm value during economic downturns. The Quarterly Review of Economics and Finance, 55, 160-175.

Wang, H. F., \& Hsu, F. C. (2009). An integrated operation module for individual risk management. European Journal of Operational Research, 198(2), 610-617.

Wang, X., Li, D., O'Brien, C., \& Li, Y. (2010). A production planning model to reduce risk and improve operations management. International Journal of Production Economics, 124(2), 463-474.

Wittayasooporn, N., Panichevaluk, A., \& Zhao, Y. (2015). PicoGrid: A web-based distributed computing framework for heterogeneous networks using java. Engineering Journal, 19(1), 153-165.

Wu, S. J., Melnyk, S. A., \& Swink, M. (2012). An empirical investigation of the combinatorial nature of operational practices and operational capabilities. International Journal of Operations \& Production Management, 32, no, 2.

Yang, L., Wang, Y., Ma, J., Ng, C. T., \& Cheng, T. (2014). Technology investment under flexible capacity strategy with demand uncertainty. International Journal of Production Economics, 154, 190-197.

Zack, M. H. (2007). The role of decision support systems in an indeterminate world. Decision Support Systems, 43(4), 1664-1674.

Zafar, H., Ko, M. S., \& Osei-Bryson, K. (2015). The value of the CIO in the top management team on performance in the case of information security breaches. Information Systems Frontiers, 18(6), $1205-1215$.

Zhao, L., \& Huchzermeier, A. (2015). Operations-finance interface models: A literature review and framework. European Journal of Operational Research, 244(3), 905-917. 